\title{
TACKLING THE GRASSROOTS: APPRAISAL OF CAREER CHOICE AND PROSPECTS OF THE STUDENTS AT A MEDICAL SCHOOL IN TANZANIA
}

\author{
Afadhali D. Russa ${ }^{1}$, Nuru. L. Mligiliche ${ }^{2}$ Rehema C.Malya $^{3}$ \\ ${ }^{1}$ Department of Anatomy, School of Medicine, Muhimbili University of Health and Allied Sciences, Dar es \\ Salaam, Tanzania. \\ ${ }^{2}$ Departments of Anatomy, School of Medicine, Weill Cornell Medical College in Qatar, Doha, Qatar. \\ ${ }^{3}$ Directorate of Library Services, Muhimbili University of Health and Allied Sciences, Dar es Salaam, \\ Tanzania
}

Correspondence to Dr. Afadhali Denis Russa, Department of Anatomy, School of Medicine, Muhimbili University of Health Sciences and Allied Sciences, P. O. Box 65001, Dares Salaam, Tanzania. Email: adrussa@yahoo.com // drussa@muhas.ac.tz. Tel: +255 755524771 Fax: +255 22215046

\begin{abstract}
Tanzania has one of the world's worst doctor-to-population ratio. Ironically, the number of medical graduates who do not practice medicine remains very high. Lack of interest and commitment of the young doctors may greatly contribute to the huge number of non-practicing doctors. We assessed medical students' career views from interest and choice during childhood, their current learning motivations, future career expectations and interest to work in the academia. One hundred and ninetyfive students halfway their first year of medical school complete a self-administered questionnaire with a verbal consent sought from each respondent. Four in every ten students had made their decision to become a doctor before or during primary school. Over 5 out of 10 students made their choice during secondary school. Majority chose medicine due to altruistic and humanity reasons and would prefer work in clinical practice in the hospital. Very few would prefer a faculty job. Knowing about the human body, controlling and managing diseases are the main motivating factors. 'Too much to learn' and 'tight schedules' were the most aspect and deterrent factors during the medical school and the medical profession in general. Attaining a higher academic honour such as a professorship would not inspire students into the academia. Majority of students make their medical career choice early in life driven by altruistic reasons. Poor learning environments disenchant them from the passion for the career. More studies are needed to assess and improve the training in medicine.
\end{abstract}

Keywords: Medical students, motivation, career prospects, Tanzania

INTRODUCTION

Tanzania has one of the least doctor-to-patient ratio of over $1: 25,000$ which is way below the currently WHO-recommended minimum ratio of $1: 10,000$ for lower income countries. Only $42 \%$ of Tanzania medical graduates work in clinical facilities while $39.6 \%$ do not practice at all
(Sikika, 2013). This huge number of medical graduates who choose not to practice medicine hampers the efforts to raise the health workforce to the required levels. While the major reason may be the inability of the public sector to absorb all medical graduates, lack of interest and

Submitted $7^{\text {th }}$ June 2016, revised on $7^{\text {th }}$ September 2016. Published online $12^{\text {th }}$ June 2017 . To cite: Russa Ad, Mligiche NL, Maiya RC. Tackling the grassroots: Appraisal of career choice and prospects of the students at a medical school in Tanzania. Anatomy Journal of Africa. 2017.6 (2): 942 -951. 
commitment of the young doctors may equally account to the mismatch. Reports of doctors who abandon the medical practicing are commonplace. In Malawi, only about $43 \%$ of graduates in medicine work in the public sectors and $40 \%$ work abroad although the trends seem to be slightly but positively changing (Zijlstra and Broadhead, 2007; Mendeville et al., 2012). In the UK, for example, close to $8 \%$ of young medical graduates leave the profession either temporarily or permanently for several reasons including factors tethered to unfavorable experiences during learning and poor preparations (Beedham, 1996). Studies have associated factors such as poor remuneration, the length of training, facility inadequacy and difficult working schedules to the poor motivation (Paice, 1997). Thus the internal brain waste because of doctors who abandon medicine is enormous, worrisome and unhealthy. Medical schools and especially biomedical sciences specialties are hit with understaffing (Mullan et al., 2011; Manyama et al., 2013), which, in the long run, will further exacerbate the severe shortage of the health workforce and will widen the knowledge and competency gaps due to below-per output of the new medical graduates both in quality and quantity. Efforts to salvage the severe shortage of doctors should start right at the selection of the candidates at enrolment into the medical school coupled with proper training in order become good future doctors
[Leon and Kolstad, 2010; Ferrinho et al., 2011; Russa and Mligiliche, 2014).

Early interest and motivation during the career choice are strong predictors of the future successfulness thereof particularly to medicine which is more of a vocation than an ordinary job (Millan et al., 2005; Leon and Kolstad, 2010; Galton, 2015). Recent views are pointing at the watered down calling in medicine and questions about the vocation in the medical profession are emerging [Astrow, 2013; Galton, 2015). For example, while medicine is supposed to be a calling, studies have shown that the choice to join the medical school and future medical career may be done by proxies including parents, guardians and teachers [(Ausman et al., 2014)]. This is potentially detrimental to one's future career motivations, growth and successfulness. There are few studies in Africa, and barely none in the East African region, that investigates the motivation and vocation of the students as to when they make their choice of the medical career. The present study aimed at investigating how and when do the medical students choose the career in medicine. And in the wake of the persistent understaffing of medical schools in Africa, we also present findings on students prospects in choosing the faculty jobs in the medical schools particularly the biomedical (basic medical) science teaching positions.

\section{MATERIAL AND METHODS}

One hundred and ninety five students-halfway their first year of medical school-were requested to complete a self-administered questionnaire. The questionnaire bore no identity and respondents were assured of the confidentiality of the information. A verbal consent was sought from the respondents and participation was completely voluntary. A faculty was available to explain to the student in regard to any queries during the filling in of the questionnaires while the filling was entirely personal. The survey involved first years that had experienced the actual life of the medical school including the most abhorred sessions of dissecting the human cadaver in the subject of anatomy and the tight laboratory schedules common in the first year of studies. Key factors assessed included when they first wished for a career in medicine, the persons who influenced their choice and factors that attracted them to the medical career. Data were entered into an excel sheet as nominal, ordinal or numerical and percentages were used to summarize demographic variables, career choice and career prospects. Qualitative outcome variables included the level of current motivation, future career plans, type of medical practice expectations and a possibility of taking up the 
faculty job. Analysis of association of ordinal data was accomplished using IBM-SPSS (version 20) using a Chi Square test and a p-value of $\leq 0.05$ were considered significant.

\section{RESULTS}

A total of 195 students successfully filled in the questionnaire that met criteria for analysis. The mean age for participants was 22 years with majority of students being male $(69.7 \%)$. Over half of the students $(51.3 \%)$ made the decision to go to the medical school during the secondary school while an appreciable $37.4 \%$ had made the choice very early on either in or before primary school.

\section{Table 1: Participants demographics and motivation to join the medical school}

\begin{tabular}{|c|c|c|}
\hline Variable & $\mathbf{N}$ & $\%$ valid \\
\hline \multicolumn{3}{|l|}{ First time to consider being a doctor } \\
\hline Before primary school & 18 & 9.2 \\
\hline During primary school & 55 & 28.2 \\
\hline During O-level & 100 & 51.3 \\
\hline During A-level & 19 & 9.7 \\
\hline During certificate/diploma college & 1 & 0.5 \\
\hline Other & 2 & 1.0 \\
\hline Total & 195 & 100.0 \\
\hline \multicolumn{3}{|l|}{ Who influenced your decision } \\
\hline Father & 19 & 9.7 \\
\hline Mother & 22 & 11.3 \\
\hline Both parents & 26 & 13.3 \\
\hline Teacher & 16 & 8.2 \\
\hline Relative/Friend & 13 & 6.7 \\
\hline Self & 85 & 43.6 \\
\hline Other/None & 14 & 7.2 \\
\hline Total & 195 & 100.0 \\
\hline \multicolumn{3}{|c|}{ Level of interest before medical school } \\
\hline Very interested & 155 & 79.5 \\
\hline Somewhat interested & 28 & 14.4 \\
\hline Was Neutral & 8 & 4.1 \\
\hline Uninterested & 2 & 1.0 \\
\hline Other & 2 & 1.0 \\
\hline Total & 195 & 100.0 \\
\hline \multicolumn{3}{|c|}{ Level of interest after joining medical school } \\
\hline Very interested & 111 & 56.9 \\
\hline Somewhat interested & 63 & 32.3 \\
\hline Neutral & 18 & 9.2 \\
\hline Uninterested & 3 & 1.5 \\
\hline Other & 0 & 0.0 \\
\hline Total & 195 & 100.0 \\
\hline
\end{tabular}


About 1 in 10 students chose the medical school in their later years of pre-university education (A-level or college). Over 4 out of every 10 students chose the medical school at their own while $37.0 \%$ were either influenced by one or both of the parents. The proportion of the students who chose the medical school by their mother's influence $(11.3 \%)$ was slightly higher than those who were influenced by the father (9.7\%) but statistically insignificant $\left(x^{2}=0.53\right.$, df $=1, p=0.47)$. One in ten students was influenced by the teachers. Relatives and friends caused an influence to $7.6 \%$ of the students. Nearly 8 out 10 students were very interested with being a doctor before joining the medical school but that proportional had fallen to 6 out of 10 at the time of the survey with the decline being statistically significant $\left(x^{2}=32.98, d f=1, p=0.0\right)$. The percentage of indifferent to uninterested students to being a doctor rose from only $2 \%$ before joining medical school to over $10 \%$ at the time of the survey (Table1).

Table 2: Reason for interest and expectations in the medical career

\begin{tabular}{|c|c|c|c|c|}
\hline \multirow[t]{2}{*}{ Variable } & \multicolumn{2}{|c|}{ First choice } & \multicolumn{2}{|c|}{ Second choice } \\
\hline & $\mathbf{N}$ & $\%$ valid & $\mathbf{N}$ & $\%$ valid \\
\hline \multicolumn{5}{|l|}{ Motivation to go to medical school } \\
\hline Inborn personal interest & 77 & 39.5 & 36 & 18.5 \\
\hline Advice from family and friends & 27 & 13.8 & 36 & 18.5 \\
\hline Because I did well in science subjects & 8 & 4.1 & 33 & 16.9 \\
\hline Because doctors make good money & 8 & 4.1 & 9 & 4.6 \\
\hline Because doctors are highly respected & 5 & 2.6 & 6 & 3.1 \\
\hline Quest to serve humanity & 52 & 26.7 & 66 & 33.8 \\
\hline Other & 18 & 8.2 & 9 & 4.6 \\
\hline Total & 195 & 99.0 & 195 & 100.0 \\
\hline \multicolumn{5}{|l|}{ Most interesting thing about studying medicine } \\
\hline Know human body structure and function & 81 & 41.5 & 43 & 22.2 \\
\hline Managing personal and own family health & 20 & 10.3 & 20 & 10.3 \\
\hline Managing diseases in society & 70 & 35.9 & 70 & 36.1 \\
\hline Contact with patients of all sorts & 14 & 7.2 & 18 & 9.3 \\
\hline Financial reward & 5 & 2.6 & 35 & 18.0 \\
\hline Other & 5 & 2.6 & 8 & 4.1 \\
\hline Total & 195 & 100.0 & 194* & 100.0 \\
\hline \multicolumn{5}{|c|}{ Most uninteresting thing about studying medicine } \\
\hline Too much to learn/memorize & 69 & 37.1 & 28 & 16.0 \\
\hline Many exams & 30 & 16.1 & 21 & 12.0 \\
\hline Tight schedules in medical school and after & 40 & 21.5 & 34 & 19.4 \\
\hline Conservative discipline & 0 & 0.0 & 8 & 4.6 \\
\hline Low pay/salary & 13 & 7.0 & 38 & 21.7 \\
\hline Other (years of training, poor teaching) & 34 & 18.3 & 46 & 26.3 \\
\hline Total & $186 *$ & 100.0 & $175^{*}$ & 100.0 \\
\hline \multicolumn{5}{|l|}{ Most uninteresting thing about being a doctor } \\
\hline Lack of personal life & 38 & 20.4 & 39 & 23.1 \\
\hline Job stress/and too much work & 84 & 45.2 & 44 & 26.0 \\
\hline Negative public perceptions of doctors & 30 & 16.1 & 14 & 8.3 \\
\hline Low income levels & 10 & 5.4 & 21 & 12.4 \\
\hline
\end{tabular}




\begin{tabular}{|l|c|c|c|c|}
\hline Conservative discipline & 3 & 1.6 & 13 & 7.7 \\
\hline Low pay/salary & 21 & 11.3 & 37 & 21.9 \\
\hline Other & 0 & 0.0 & 1 & 0.6 \\
\hline Total & $186^{*}$ & 100.0 & $169 *$ & 100.0 \\
\hline
\end{tabular}

*Fewer respondents to the question than the total sample

"In-born personal interest" and "Quest to serve humanity" were the most cited motivations for choosing the medical profession $(39.5 \%$ and $26.7 \%$ respectively) while "Money" ,"Respect" and Excellent Performance in High School" were least cited as the motivations $(4.1 \%, 2.6 \%$ and $4.1 \%$ respectively). When the first and second choices were considered together, "in-born personal interest" and "quest to serve humanity" still scored highest as the motivating factors. Excellent graded in high school was strongly favoured by many participants as the second motivating factor equalling the score of "in-born personal interest" (18.5\%). Knowing the human body, controlling and managing diseases were the most expectations from the participations scoring $41.5 \%$ and $35.9 \%$ respectively whereas financial reward scored only $2.6 \%$. Nearly 4 out of 10 students thought "too much to learn" was the most boring aspect of being a medical student but no student $(0 \%)$ thought medicine was a conservative discipline. Over 2 in every 10 students saw considered the tight schedules as a deterrent in the medical school and the medical job. Again poor financial reward did not seem to bother most of the students (only $7.0 \%$ ). There were other miscellaneous factors constituting $18.3 \%$ of participants which included the "Many years of training to be a doctor" and "Poor teaching methods in medical school" (Table 2).

Table 3: Career goals and expectations

\begin{tabular}{|l|c|c|c|c|}
\hline \multirow{2}{*}{ Variable } & First choice & \multicolumn{2}{c|}{ Second choice } \\
\cline { 2 - 5 } & N & \% valid & N & \% valid \\
\hline After graduation, area you intend to work in & 26 & 13.3 & 79 & 42.0 \\
\hline Biomedical sciences/academic & 134 & 68.7 & 35 & 18.6 \\
\hline Clinical practice & 29 & 14.9 & 44 & 23.4 \\
\hline Medical administration, policy etc & 3 & 1.5 & 10 & 5.3 \\
\hline Non-medical (business, journalism etc) & 0 & 0.0 & 5 & 2.7 \\
\hline Political position & 2 & 1.0 & 13 & 6.9 \\
\hline Religious ministry & 1 & 0.5 & 2 & 1.1 \\
\hline Other & 195 & 100.0 & $188 *$ & 100.0 \\
\hline Total & \multicolumn{5}{|l|}{} \\
\hline Type of workplace you intend to work for & 14 & 7.2 & 40 & 20.6 \\
\hline Medical school/academia in health & 107 & 54.9 & 34 & 17.5 \\
\hline General government hospital & 24 & 12.3 & 41 & 21.1 \\
\hline Private practice & 14 & 7.2 & 20 & 10.3 \\
\hline International missionary & 6 & 3.1 & 10 & 5.2 \\
\hline Policy at Ministry of Health & 20 & 10.3 & 30 & 15.5 \\
\hline Research Institute & 9 & 4.6 & 15 & 7.7 \\
\hline Public health/administration & 1 & 0.5 & 4 & 2.1 \\
\hline Other & 195 & 100.0 & $194 *$ & 100.0 \\
\hline Total &
\end{tabular}

*Fewer respondents to the question than the total sample 
Table 4: Career in the biomedical academia

\begin{tabular}{|c|c|c|c|c|}
\hline \multirow[t]{2}{*}{ Variable } & \multicolumn{2}{|c|}{ First choice } & \multicolumn{2}{|c|}{ Second choice } \\
\hline & $\mathbf{N}$ & $\%$ valid & $\mathbf{N}$ & $\%$ valid \\
\hline \multicolumn{5}{|c|}{ If you chose biomedical sciences, discipline you would go for } \\
\hline Anatomy & 31 & 25.2 & 29 & 25.2 \\
\hline Biochemistry & 14 & 11.4 & 14 & 12.2 \\
\hline Microbiology/immunology & 11 & 8.9 & 11 & 9.6 \\
\hline Pathology & 14 & 11.4 & 15 & 13.0 \\
\hline Parasitology/Entomology & 3 & 2.4 & 6 & 5.2 \\
\hline Pharmacology & 8 & 6.5 & 16 & 13.9 \\
\hline Physiology & 40 & 32.5 & 21 & 18.3 \\
\hline Other & 2 & 1.6 & 3 & 2.6 \\
\hline Total & 123* & 100.0 & $115^{*}$ & 100.0 \\
\hline \multicolumn{5}{|c|}{ Motivation to choose career in biomedical sciences } \\
\hline Fits my interest and aptitude & 70 & 56.5 & 25 & 25.3 \\
\hline Prestige in society & 1 & 0.8 & 12 & 12.1 \\
\hline Higher chance to become a professor & 1 & 0.8 & 8 & 8.1 \\
\hline Want to be a prominent researcher & 39 & 31.5 & 35 & 35.4 \\
\hline Little chance of malpractice/job security & 2 & 1.6 & 7 & 7.1 \\
\hline Not motivated in biomedicals & 10 & 8.1 & 3 & 3.0 \\
\hline Biomedicals pay more & 1 & 0.8 & 7 & 7.1 \\
\hline Other & 0 & 0.0 & 2 & 2.0 \\
\hline Total & $124 *$ & 100.0 & 99* & 100.0 \\
\hline \multicolumn{5}{|c|}{ Strongest motivation to choose a career in clinical discipline } \\
\hline To fulfill my interest and aptitude & 71 & 37.2 & 89 & 50.6 \\
\hline Helping many patients with diseases & 114 & 59.7 & 63 & 35.8 \\
\hline High social prestige / esteem & 0 & 0.0 & 7 & 4.0 \\
\hline Clinicals pay more & 5 & 2.6 & 15 & 8.5 \\
\hline \multirow[t]{2}{*}{ Other } & 1 & 0.5 & 2 & 1.1 \\
\hline & $191^{*}$ & 100.0 & $176^{*}$ & 100.0 \\
\hline
\end{tabular}

*Fewer respondents to the question than the total sample

Majority of the students overwhelmingly preferred clinical practice $(68.6 \%)$ as their first choice versus other medical related jobs such as administration or policy (14.9\%) and the academia in biomedical sciences (13.3\%). A trace of students $(3.0 \%)$ would abandon the medical career altogether and enter into business, journalism or even religious ministry but not politics. When asked for their second choice, a job in biomedical science academia was favored by the majority of participants (42.0\%) which is higher than medical administration or policy $(23.4 \%)$ and clinical practice $(18.6 \%)$. A huge number $(54.9 \%)$ preferred working in the general government hospitals significantly higher than those who would work in the private hospital $(12.3 \%)$, medical research institutes $(10.3 \%)$ or medical schools (7.2\%) (Table 3).

When assessed on the possibility of working in biomedical academia, the students chose those departments whose subjects are taught in the first year with Physiology (32.5\%), Anatomy $(25.2 \%)$ and Biochemistry (11.4\%) favored in that order. When the second choice was considered, preferences changed slightly with 
Anatomy (25.2\%) scoring highest followed by Physiology (18.3\%) and Biochemistry (12.2\%). While respondents could have limited exposure thereof, biomedical courses in the second year were not strongly favored but an appreciable proportion chose Pathology (11.4\%), Microbiology (8.9) and Pharmacology (6.5\%). Choosing a career in biomedicine was due to interest and aptitude (56.5\%) and becoming a renowned researcher $(31.5 \%)$. Attainment of a professorship status or prestige in the society both at $0.8 \%$ apiece was not a motivation for students to choose a career in biomedicine or even in clinical sciences. Similar reasons for choosing to join the medical school would be used to choose the type of job after graduation which included helping patients $(59.7 \%)$ and personal satisfaction $(37.2 \%)$ as the major ones and, likewise, less that $3 \%$ of respondents would think the medical job pays well (Table 4).

\section{DISCUSSION}

The present work has shown that students make their medical career choice at a tender age before they graduate from secondary education. This early career choice may be interpreted as a vocational choice or a calling (Millan et al., 2005). A big proportion of respondents chose the medical career at their own decision. This is important in respect of the career achievement (Gąsiorowski et al., 2015). Other studies have shown that children are either persuaded or forced to choose the career according to the wishes of the parents, guardians and even teachers but this tendency may be consequential in terms of career dissatisfaction (Ferrinho et al., 2011; Ausman et al., 2013). In the present study nearly 4 out of every 10 students were influenced by one or both parents-generally higher than it was reported elsewhere (Al-Dabal, 1998). It should be noted that the parental influence can either be of coercive or persuasive type-both with delicate differences and effects to the child's career. In the present study the distinction of the type of influence was not established due to the newness of the respondents to the questionnaires and research in general. Although statistically insignificant, more students were influenced by mothers than their fathers-which could be due to the fact that mother spend more time with children or because there are more single parent families reared by women than those reared by men. In agreement with other studies, a large number of students become disenchanted after entering the medical school and this disenchantment trend may continue even after graduation as they assume the actual career [Leon and Kolstad, 2010; Gąsiorowski et al., 2015). Studies have suggested that the mentoring and role modelling by the faculty is vital for student learning achievements and career success (Tosteson, 1979; Skeff and Mutha, 1998; Mwachaka and Mbugua, 2010) but in many instances it is either insufficient or inexistent altogether (Cruess et al., 2008; Benbassat, 2014). The decline in the level of enthusiasm after entering the medical school is worrisome and is likely to be due to the poor learning approaches in universities, experiencing the actual reality of the medical school or simply the loss of sheer excitement and delusions after obtaining admission to the medical school.

It is propitious that money and prestige - the two most common career motivating elementswere not the main reasons to choose the medical career. The opposite would mean that failure to achieve these satisfactions, which almost always is the case with health jobs, one's career prospects would be perilous. Our findings on the influence of money and prestige as motivations are consistent with previous reports which have been considered to be the key to a successful medical career. For years, the medical profession has demanded vocational virtues in patience, altruism, self denial and humility (Borges et al., 2013; Galton, 2015) but some studies contradict these assertions (Girasek et al., 2011; ; Astrow, 2013). Therefore, these core values may not 
flourish when the expectations are largely pegged on money and prestige. The fact that most respondents were motivated by being able to serve humanity and inborn personal interests need to be nurtured in order to created doctors with a true calling to the profession. Previous reports found that the motives to choosing a medical career may change during the course of the training (Leon and Kolstad, 2010; Gąsiorowski et al., 2015). Consistent with previous results, tight schedules and too much information to learn in form of memorization were abhorred by many respondents but respondents did not think medicine is inherently conservative. This may mean that, probably, the advent of newer teaching and learning methods, albeit insufficient, tend to excite the students.

Only a little less than 1 in 10 respondents would prefer a faculty position as compared to more than 5 in 10 who preferred working in a general government hospital. This study affirms the precarious situation and does not point to any hope for the good future regarding the consistent poor staffing in medical schools particularly in Africa. Our work goes further to compare clinical and biomedical discipline preferences and the situation is even bleaker for the teaching jobs in biomedical disciplines. In agreement with our findings, several studies have shown consistent understaffing of universities particularly in biomedical disciplines is sub-Saharan Africa (Mullan et al., 2011; Manyama et al., 2013). Deliberate efforts coupled with tangible solutions by university administrations and policy makers at institutional, national and regional levels are needed to remedy this anomaly that threatens the healthcare provision on the African continent. While the major biomedical courses in anatomy, physiology and biochemistry are taught in similar conditions, the clear preference in the order of physiology, anatomy and biochemistry cannot be underestimated. Possible reasons of varying preferences are previously reported including inspiring students and role modelling (Tosteson, 1979; Skeff and Mutha, 1998; Cruess et al., 2008; Mwachaka and
Mbugua, 2010; Gąsiorowski et al., 2015) and therefore universities should quickly adjust to the current challenges of educational and training needs. The number of students who would leave the medical profession was apparently insignificant (3.0\%) but still raising eyebrows - given the fact that that most medical students start to lose interest during their senior years of study and therefore these results may not be directly informative Attaining a higher academic honour such as a professorship did not inspire students into the academia. This is glimmer than reported elsewhere in which just a little more than half of respondent viewed taking a faculty job positively (Greenberg et al., 2013). Innovative approaches need to be devised in order to keep the succession and supply of new faculty into our medical schools. Raising faculty morale, student mentorship, role modelling and retaining quality graduates as extensively reviewed previously (Bickel and Brown, 2005; Mwachaka and Mbugua, 2010) would be of enormous impact. In conclusion, majority of students make their medical career choice early in life driven by altruistic reasons which are important for a successful career. Poor learning environments disenchant them from the passion for the career which, in a long run, contributes to the shortage of health workforce both qualitatively and quantitatively. More studies are needed to assess, evaluate and improve the training in medicine including the entry criteria other than secondary and high school grades, role modelling and mentorship in order to improve the health workface in the country and beyond.

\section{Acknowledgement}

We are very grateful to MUHAS medical students of the 2014-15 academic years for their generous participation in the present study. We also wish to extend our gratitude to the staff of the Department of Epidemiology and Biostatistics, Weill Cornell Medical College in Qatar, Doha for their technical assistance in data management and analysis. 


\section{Competing interest}

We have no competing interest to declare.

\section{REFERENCES}

1. Al-Dabal BK. 1998. Choosing a medical career: what influences secondary school female graduates? Journal of Family \& Community Medicine 5, 53-59.

2. Astrow AB. 2013. Is Medicine a Spiritual Vocation? Society 50, 101-105.

3. Ausman J, Javed A, Ahmed S, et al. 2013. Factors influencing career choice in a medical school in the United Arab Emirates. Education in Medicine Journal 5, 14-20.

4. Beedham T. 1996. Why do young doctors leave medicine? Br. J. Hosp. Med 55, 699-701.

5. Benbassat J. 2014. Role modeling in medical education: the importance of a reflective imitation. Acad Med 89, 550-554.

6. Bickel J, Brown AJ. 2005. Generation X: implications for faculty recruitment and development in academic health centers. Acad Med 80, 205-210.

7. Borges NJ, Manuel RS, Duffy RD. 2013. Specialty interests and career calling to medicine among first-year medical students. Perspect Med Educ 2, 14-17.

8. Cruess SR, Cruess RL, Steinert Y. 2008. Role modelling-making the most of a powerful teaching strategy BMJ 718-721.

9. Ferrinho P, Sidat M, Fresta MJ, et al. 2011. The training and professional expectations of medical students in Angola, Guinea-Bissau and Mozambique. Hum Resour Health, 9:9.

10. Galton DJ. 2015. Is medicine still a profession? QJM: An International Journal of Medicine, 092015, $1-3$.

11. Gąsiorowski J, Rudowicz E, Safranow K. 2015. Motivation towards medical career choice and future career plans of Polish medical students. Adv Health Sci Educ Theory Pract 20, 709-725.

12. Girasek E, Molnar R, Eke E, Szo' cska M. 2011. The medical career choice motivations-results from a Hungarian study. Central European Journal of Medicine 6,502-509.

13. Greenberg RB, Ziegler $\mathrm{CH}$, Borges NJ, Elam CL, Stratton TD, Woods S. 2013. Medical student interest in academic medical careers: a multi-institutional study. Perspectives on Medical Education 2, 298-316.

14. Leon BK, Kolstad JR. 2010. Wrong schools or wrong students? The potential role of medical education in regional imbalances of the health workforce in the United Republic of Tanzania. Hum Resour Health 8:3.

15. Mandeville KL, Bartley T, Mipando M. 2012. Future career plans of Malawian medical students: a cross-sectional survey. Hum Resour Health 10:29.

16. Manyama M, Mshana S, Kabangira R, Konje E. 2013. Shortage of faculty in medical schools in Tanzania: A case study at the Catholic University of Health and Allied Health Sciences. African Journal of Health Professions Education 5, 95-97.

17. Millan LR, Azevedo RS, Rossi E, De Marco OLN, Millan MPB, de Arruda PCV. . What is behind a student's choice for becoming a doctor? Clinics 60, 143-150.

18. Mullan F, Frehywot S, Omaswa F, et al. 2011. Medical schools in sub-Saharan Africa. Lancet 377(9771), 1113-1121.

19. Mwachaka PM, Mbugua ET. 2010. Specialty preferences among medical students in a Kenyan university. The Pan African Medical Journal, 5:18.

20. Paice E. 1997. Why do young doctors leave the profession? J. Royal. Society Med 90, 417-418.

21. Powell A, Boakes J, Slater P. 1987. What motivates medical students: how they see themselves and their profession. Medical Education 21, 176-182. 
22. Russa AD, Mligiliche L. 2014. Inspiring Tanzanian medical students into the profession: appraisal of cadaveric dissection stress and coping strategies. Ital J Anat Embryol 119, 268-276.

23. Sikika, 2013. Where are the Doctors? Tracking Medical Doctors in Tanzania. Dar es Salaam: Jamana Printers, ISBN 978-9987-9777-1-0. URL: http://sikika.or.tz/wp-content/uploads/2013/11/PracticeStatus-of-Medical-Graduates-FINAL.pdf (accessed December, 2016).

24. Skeff KM, Mutha S. 1998. Role models-guiding the future of medicine. N Engl J Med 339, 20152017.

25. Tosteson DC. 1979. Learning in medicine. N Engl J Med 301, 690-694.

26. Zijlstra EE, Broadhead RL. 2007. The College of Medicine in the Republic of Malawi: towards sustainable staff development. Hum Resour Health 5:10. 